American Journal of Agricultural and Biological Sciences 2 (4): 291-298, 2007

ISSN 1557-4989

(C) 2007 Science Publications

\title{
Bioaccumulation of Cr(III) ions by Blue Green-alga Spirulina sp. Part II. Mathematical Modeling
}

\author{
${ }^{1}$ Katarzyna Chojnacka and ${ }^{2}$ Piotr M. Wojciechowski \\ ${ }^{1}$ Institute of Inorganic Technology and Mineral Fertilizers, Wrocław University of Technology \\ ul. Smoluchowskiego 25, 50-372 Wrocław, Poland \\ ${ }^{2}$ Department of Chemistry, Wrocław University of Technology \\ ul. Smoluchowskiego 23, 50-372 Wrocław, Poland
}

\begin{abstract}
In the present paper bioaccumulation of $\mathrm{Cr}(\mathrm{III})$ ions by blue-green algae Spirulina sp. is discussed. We found that the process consisted of two stages: passive in which $\mathrm{Cr}$ (III) ions are bound to the surface of cells, identical with biosorption and active, metabolism-dependent, in which $\mathrm{Cr}$ (III) ions are transported into the cellular interior. The passive stage occurs in both living and non-living cells and the active - only in living biomass. Two distinctive mathematical models of the process were proposed. The first was physical model basing on the identified mechanism of the process. In the second model, artificial neural networks were proposed.
\end{abstract}

Key words: Bioaccumulation, mechanism, kinetics, mathematical modeling

\section{INTRODUCTION}

Bioaccumulation is defined as the transport of pollutants (organic or inorganic) into the cellular interior $^{[1]}$. Due to the complexity of the process, the problem lies on the boundary of microbiology, chemistry and bioprocess engineering ${ }^{[2],[3]}$. Bioaccumulation can find an application only in treatment of effluents containing low level of pollutants (below toxic level for a given organism), containing simultaneously also nutrients (inorganic or organic source of carbon, nitrogen, phosphorus, sulfur etc. $)^{[4]}$.

The mechanism of heavy metal ions binding and toxic effect caused by them differ between microbial species and heavy metal ions ${ }^{[5]}$. Also, chemical nature of pollutants has the fundamental effect on the bioaccumulation process ${ }^{[6]}$. Heavy metal ions are usually transported via protein carriers into the cellular interior. The quantity of metal ion transferred into the cellular interior also depends on the concentration of metal ion in the proximity of transporting channel ${ }^{[7]}$. The mechanism of bioaccumulation of heavy metal ions by microorganisms is still not understood. The process therefore, has found no practical application so $\operatorname{far}^{[8],[9],[10]}$. There are only few systematic studies in the field of the mechanism, rules, quantitative description of adsorption process and process solutions, while many problems remain unresolved, resulting in limited industrial application of this method of wastewater treatment $^{[11]}$.

The idea of the application of microalgae in bioaccumulation of heavy metal ions was proposed many years ago; for the first time by Oswald and Gootas in the year $1957^{[12]}$, but this topic has gained attention only recently ${ }^{[13],[14]}$. Wastewater treatment using living microalgae may also simultaneously eliminate nitrogen and phosphorus compounds that are responsible for eutrophication ${ }^{[15],[10]}$. In the process of bioaccumulation, the concentration of metal ions may decrease below the level reached in biosorption, although longer time is required ${ }^{[16],[17]}$.

Literature reports that microalgae are more efficient in heavy metal ions binding than bacteria or fungi ${ }^{[18]}$. Probably because the process carried out by living microalgae is associated with metabolic activity and photosynthesis $^{[18],[19],[20],[21],[22]}$. Microalgae possess high tolerance towards elevated concentration of heavy metal ions. In the presence of these ions, overexpression of specific metal-binding peptides and proteins (i.e. phytochelatins) occurs, that results from their physiological adaptation, since these organisms frequently live in salty environment ${ }^{[17],[23],[24]}$.

The majority of studies on bioaccumulation of heavy metal ions by microalgae (similarly as the majority of works on bioaccumulation itself) report only the final concentration of metal ions. However,

Corresponding Author: Institute of Inorganic Technology and Mineral Fertilizers, Wrocław University of Technology; ul. Smoluchowskiego 25, 50-372 Wrocław, Poland; e-mail: katarzyna.chojnacka@pwr.wroc.pl; telephone: $+48-713203902$; fax: $+48-713203469$ 
only few works provide quantitative kinetic description of the process and investigate its mechanism. The majority of works only report the quantity of metal ions bound by the biomass without quantitative equilibrium and kinetic data, and concern mainly the following microalgal strains: Chlorella vulgaris ${ }^{[25]}$, Chlamydomonas reinhardii ${ }^{[26]}$ as the model algae ${ }^{[9],[18]}$.

There are only few models describing bioaccumulation in the literature. The most thoroughly documented was the model elaborated by Prince and Ting ${ }^{[1],[27],[28],[29]}$ that assumed two steps of bioaccumulation process: 1) preliminary, quick binding of metal ions to cellular wall; 2) slower transport through cellular membrane. The suitability of this model was confirmed for the following strains of unicellular algae: Chlorella pyrenoidosa, Chlorella vulgaris and Chlamydomonas reinhardti.

The aim of the present work was to investigate the mechanism and propose a mathematical description of bioaccumulation process performed by microalgae Spirulina sp., as it was shown previously ${ }^{[30]}$, that this blue-green alga is suitable for heavy metal ions removal from large volume, diluted effluents via bioaccumulation. Bioaccumulation of $\mathrm{Cr}$ (III) ions was studied in typical liquid growth medium in artificially illuminated stirred tank photobioreactor.

\section{MATERIALS AND METHODS}

Microorganism and media composition: Spirulina $s p$., a blue-green alga, obtained from Sigma (USA) was used in this study. Spirulina was grown in a photobioreactor (working volume $1 \mathrm{~L}$ ) at $35^{\circ} \mathrm{C}$ in Zarrouk liquid medium ${ }^{[31]}$ containing $\left(\mathrm{g} \mathrm{L}^{-1}\right): \mathrm{NaNO}_{3}$, 2.50; $\mathrm{K}_{2} \mathrm{HPO}_{4}, 0.50 ; \mathrm{NaHCO}_{3}, 10.00 ; \mathrm{NaCl}, 1.00$; $\mathrm{MgSO}_{4} \cdot 7 \mathrm{H}_{2} \mathrm{O}, 0.2 ; \mathrm{CaCl}_{2} \cdot 2 \mathrm{H}_{2} \mathrm{O}, 0.02 ; \mathrm{FeSO}_{4} \cdot 7 \mathrm{H}_{2} \mathrm{O}$, 0.01 enriched with glucose 1.00 and $\mathrm{Cr}$ (III) ions (3.1$\left.25.6 \mathrm{mg} \mathrm{kg}^{-1}\right)$ under illumination $\left(32.7 \mathrm{~W} \mathrm{~m}^{-2}\right)$ with photoperiod of 12 hours light and 12 hours dark. Sampling $(10 \mathrm{~mL})$ was performed over a period of ca. 100 hours. The construction of the photobioreactor was presented previously ${ }^{[32]}$.

Analytical methods: All samples were filtered immediately through prewashed and preweighed paper filters (No 2), and cell dry weights were determined after drying filters at $80^{\circ} \mathrm{C}$ until the samples reached the constant weight. Cell concentration was determined with a UV-160A UV-visible recording spectrophotometer (Shimadzu) at a wavelength of 560 $\mathrm{nm}$ (the value independent on pigment concentration). Light intensity was measured with PU 550 Metro Blansko luxmeter. The concentration of $\mathrm{Cr}$ (III) ions was determined by Inductively Coupled Plasma Spectrometry ICP-OES plasma spectrometer (Philips Scientific PU 7000).

Batch bioaccumulation: Cultures were initiated with ca. $0.25 \mathrm{~g}$ of Spirulina cells in the form of lyophilisate that was used to inoculate the medium $(1 \mathrm{~L})$, and grown at $32.7 \mathrm{~W} \mathrm{~m}^{-2}, \mathrm{c}_{\mathrm{Cr}(\mathrm{III})}=3.1-25.6 \mathrm{mg} \mathrm{kg}^{-1} 35^{\circ} \mathrm{C}$. The culture was aerated with sterilized air $(0.1 \mu \mathrm{m}$ filter $)$ at a flow rate $4.0 \mathrm{~mL} \mathrm{~s}^{-1}$.

Identification of bioaccumulation mechanism: In order to assess the contribution of passive and active stage of bioaccumulation, as well as to identify the mechanism of the process, the concentration of $\mathrm{Cr}$ (III) in the solution, on surface of cells and inside of them was obtained at different interval of time. The suspension of cells $(10 \mathrm{~mL})$ was sampled. The cells were removed by centrifugation. Supernatant was analyzed for the content of $\mathrm{Cr}$ (III) ions in the solution. The cells were incubated in $5 \mathrm{~mL}$ of $0.1 \mathrm{~mol} \mathrm{~L}^{-1} \mathrm{HNO}_{3}$ for 5 minutes. It was proved previously ${ }^{[33]}$ that nitric acid at this concentration enabled to desorbs almost all the metal ions bound by the cells without destruction of the biomass. The suspension was then centrifuged. The concentration of metal ions was analyzed in the supernatant. The remaining biomass was used for determination of metal ions concentration inside the cells. The biomass was digested in Microwave Digestion System CEM 2000 (USA) in closed teflon bombs with $5 \mathrm{~mL}$ concentrated $\mathrm{HNO}_{3}$. Under these conditions the cells were completely mineralized. The analysis of post-digestion solutions enabled to assess the total content of metal accumulated in cells. The correctness of this procedure was then confirmed by the mass balance of $\mathrm{Cr}$ (III) ions in the system.

Modelling: The parameters of the physical model were determined by Mathematica software from Wolfram Research, Inc. The model of artificial neuron network was elaborated with the use of standard procedures included in MATLAB ${ }^{\circledR}$ software ver. 7.2 from the MathWorks, Inc.

\section{RESULTS AND DISCUSSION}

Mechanism: When discussing the process of bioaccumulation it is necessary to precisely define the subsequent stages. The first step of the process is metal ions binding to the cellular surface. The mechanism of this stage is identical with biosorption and in the present work is described with the term of the passive stage of bioaccumulation, since no metabolic activity of 
cells was observed. Subsequently, metal ions are transported into the cellular interior (specific bioaccumulation). The process requires energetic expenditures and thus metabolic activity of cells and therefore is described as the active stage of bioaccumulation. Bioaccumulation is thus a combination of stages: passive and active. It is the process that consumes cellular energy for i.e. active transport of metal ions and for cellular growth and synthesis of metal-binding proteins. The consequence is lower process rate and the process is much slower than biosorption alone.

In order to confirm the hypothesis concerning the mechanism of bioaccumulation, the experiment was performed in which metal ions present on the cell surface were distinguished from those, present in its interior. The study was conducted for the initial concentration of $\mathrm{Cr}$ (III) ions $25.6 \mathrm{mg} \mathrm{kg}^{-1}$. In this experiment, the quantity of metal ion bound reversibly (in the passive stage) with the biomass (elutable with $0.1 \mathrm{~mol} \mathrm{~L}^{-1} \mathrm{HNO}_{3}$ ), the quantity of metal ions bound irreversibly (in the active stage) with the biomass (nonelutable with $0.1 \mathrm{~mol} \mathrm{~L}^{-1} \mathrm{HNO}_{3}$ ), that was determined after biomass digestion with concentrated $\mathrm{HNO}_{3}$, as well as metal ions concentration in solution were investigated in time (Fig. 1). Basing on this experiment, it was found that the quantity of metal ions bound with the biomass reversibly (via biosorption) increased during the initial 7 hours, even though biosorption itself is the rapid process, with the equilibrium reached within few minutes. It was possible due to biomass growth and thus the increase of the biomass surface that was available to metal ions. After $7^{\text {th }}$ hour of the process, the quantity of metal ions bound passively decreased, as the result of metabolic activity and the quantity of metal ions bound actively increases. The amount of metal ions bound reversibly decreased below $2 \mathrm{mg} / \mathrm{kg}$ after 55 hours. Chromium ions were transported into cellular interior with the simultaneous release of metal ions binding sites on its surface. The quantity of metal ions bound inside the cells increased during the first 55 hours of the process, while the concentration of metal ions in the solution remained unchanged since $30^{\text {th }}$ hour. The process was finished after 55 hours. At this moment metal bound by the biomass was present mainly in its interior, and the surface concentration of metal ions was very low.

Beside the fact that metal ions binding to the cellular surface, similarly as biosorption itself, was the rapid process, ions binding in the passive stage was slower, it endured 7 hours due to biomass growth. However, external metal uptake stabilized during the first several minutes (Fig. 2).
The experiments in which the quantity of metal ions bound to the cellular surface was distinguished from that bound inside the cells were carried out in order to identify the mechanism of bioaccumulation and confirmed preliminary hypothesis that bioaccumulation process consists of two stages:

1. passive (biosorption) - rapid stage, lasting for several hours, during which metal ions bind to the surface of cellular wall of microalgae;

2. active (adequate bioaccumulation) - stage lasting for tens of hours (in this case ca. 55 hours); in this stage, metal ions were transported into the cellular interior, with the simultaneous release of metal binding sites on cellular surface and binding of the subsequent metal ions as well as metal ions transport. By the end of the process almost all the metal ions were removed from the biomass surface.

When considering the time of conduction of bioaccumulation process, it is necessary to take into account not only metal ions concentration in the solution, but also metal ions concentration on the surface of cells (passive capacity). After 24 hours of the process, the concentration of chromium ions in the solution stabilized, but bioaccumulation process was not finished. Metal ions were transported into the cellular interior. After this process had been finished, the passive capacity was low and the biomass could be directly used in another process of metal ions removal as the biosorbent. We assumed that the passive sorption process on the cellular surface is performed in a very similar way in the case of living and non-living cells. However, the active stage of bioaccumulation can be carried out only by living cells.

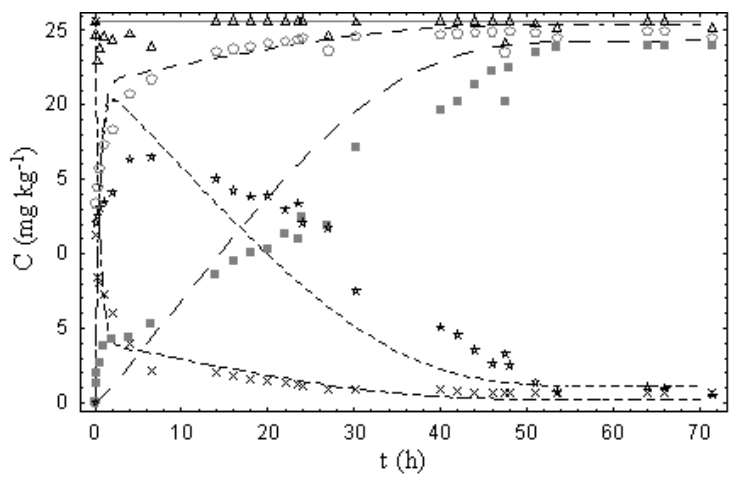

Fig. 1: Location of chromium ions in the process of bioaccumulation, $\mathbb{X}-c_{M e}$ (chromium ions concentration in solution), $\mathbf{H}-c_{\text {pas }}$ (chromium ions bound in the process of passive biosorption), $-C_{\text {act }}$ (chromium ions bound in the process of active bioaccumulation), $0-c_{\text {pas }}+c_{\text {act }}$ (total concentration of metal ions bound with the biomass), $\Delta-c_{M e}+c_{\text {pas }}+c_{a c t}$ (the balance of chromium ions present in the system (in the solution and bound with the biomass). 


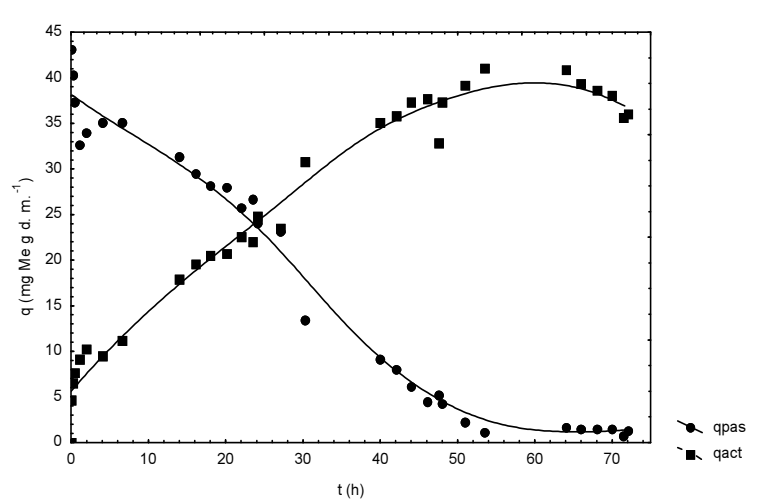

Fig. 2: Metal ions uptake in the passive $\left(q_{\text {pas }}\right)$ as well as in the active $\left(q_{a c t}\right)$ stage of bioaccumulation.

\section{KINETIC MODELS}

Physical model: Generally in bioaccumulation process the following stages, each of different biochemical nature occur. All these processes are associated with mass transfer: sorption to the cellular surface, active transport through cellular membrane into inside of the cells, accumulation inside of the cells.

In the first stage, metal ions present in the solution, are reversibly bound with the free surface of the biomass. The equilibrium between the concentration of metal ions in the solution at the surface of a cell $c_{M e}$ and the concentration of metal adsorbed on its surface $c_{\text {pas }}$ can be described with Langmuir equation ${ }^{[34]}$ :

$$
q=\frac{q_{\max } \cdot c_{M e}}{1+b \cdot c_{M e}}
$$

for low concentration of metal ions, the above equation can be simplified to the following linear dependence:

$$
c_{M e}=a \cdot c_{\text {pas }},
$$

where $a$ is dimensionless adsorption coefficient and $\mathrm{c}_{\mathrm{pas}}$ is the concentration of $\mathrm{Cr}$ (III) ions adsorbed on the surface on the biomass.

In the second stage, metal ions adsorbed on the cellular surface, after binding with the receptor sites on carrier proteins, are transported through cellular membrane. After passing through cellular membrane, metal ions are released to cytoplasm and/or complexed with proteins are transported to organelles where they become accumulated. The presented mechanism of bioaccumulation can be described by three consecutive equilibrium reactions:

$$
c_{M e} \underset{k_{\text {pas }}}{\stackrel{k_{\text {pas }}}{\Leftrightarrow}} c_{\text {pas }} \stackrel{k_{t}}{\stackrel{k_{i t}}{\Leftrightarrow}} c_{\text {tran }} \underset{k_{-a}}{\stackrel{k_{a}}{\Leftrightarrow}} c_{\text {accum }}
$$

where: $c_{M e}$ - concentration of $\mathrm{Cr}$ (III) ions in the solution, $c_{\text {pas }}$ - concentration of chromium adsorbed on the surface of the biomass, $c_{\text {tran }}$ - concentration of chromium bound with carrier proteins, $c_{\text {accum }}-$ concentration of chromium ions accumulated inside the cells.

The model becomes complete after taking into consideration the concentration of cells as the function of time. In the literature, four cases are considered. The most frequently it is assumed that metal is accumulated by living cells without cellular growth, accumulated by living cells in the phase of linear growth, accumulated by cells in logarithmic phase. Growth of cells is described with Monod equation in the case of limiting concentration of substrates. Monod equation was used previously to describe growth rate of cells ${ }^{[30]}$ :

$$
\frac{d X}{d t}=\mu X
$$

where $X$ is the concentration of organisms and $\mu$ is the specific growth rate. In the case of nutrient limited cultures, the specific growth rate is given by the following expression:

$$
\mu=\mu_{\max } \cdot \frac{S}{K_{S}+S}
$$

where $\mu_{\max }$ is the maximum specific growth rate, $K_{S}$ is a saturation constant and $S$ is the substrate concentration.

Metal ions can have an effect on cellular growth, that could be either stimulating or inhibiting. Since the rate of sorption process is proportional to the surface of cells, and the rate of accumulation inside of cell is proportional to the volume of cells, it is significant to assess the character of biomass growth.

In mathematical description of microbial processes, common practice is to simplify models in order to reduce the number of model parameters. Since bioaccumulation is associated with active transport through cellular membrane and bioaccumulation of chromium ions in cytoplasm is carried out by specific proteins, de facto present inside the cells, it was assumed that the rate of these processes might be expressed by a single constant describing the rate of active transport $k_{a c t}$.

$$
c_{M e} \underset{k_{\text {-pas }}}{\stackrel{k_{\text {pas }}}{\Leftrightarrow}} c_{\text {pas }} \underset{k_{\text {-act }}}{\stackrel{k_{a c t}}{\Leftrightarrow}} c_{a c t}
$$

When proposing a model it is significant to check experimentally which out of postulated reactions are reversible and which could be considered as irreversible under experimental conditions. In order to investigate this, the cells that were bound with metal ions were eluted with $0.1 \mathrm{~mol} \mathrm{l}^{-1} \mathrm{HNO}_{3}$ (the part of metal ions bound reversibly with the cells) and with concentrated $\mathrm{HNO}_{3}$ (the quantity of metal ions bound reversibly and irreversibly with the biomass). Therefore we concluded that the stage of metal ions binding to the cellular surface (adsorption) can be assumed as reversible. In the consequence it was assumed that $k_{-p a s} \gg k_{\text {-act }}$. 
In a hypothetical case, if all $\mathrm{Cr}$ (III) ions were removed from the solution, the process of bioaccumulation by Spirulina $s p$. could be assumed as irreversible and non-equilibrium process and the value of $k_{\text {-act }}$ would equal zero. This means that the reaction could be written as follows:

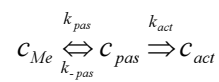

It was assumed that biosorption is the first stage of bioaccumulation. Previously, biosorption of $\mathrm{Cr}$ (III) ions to Spirulina $s p$. cells was described with the following Langmuir equation $^{[34]}$ :

$$
q=\frac{2.22 \cdot c_{M e}}{1+1.62 \cdot c_{M e}}
$$

On the basis of microscopic observations it was observed that during microbial growth, the ratio of cellular mass to their surface is constant. The equation of mass balance and kinetic equations describing concentrations of all forms of $\mathrm{Cr}$ (III) ions were proposed:

$$
\begin{gathered}
c_{M e}(t)+c_{p a s}(t)+c_{a c t}(t)=c_{M e}(t=0) \\
\frac{d c_{M e}}{d t}=-k_{p a s} \cdot X(t) \cdot c_{M e}(t)+k_{-p a s} \cdot X(t) \cdot c_{p a s}(t) \\
\frac{d c_{p a s}}{d t}=k_{p a s} \cdot X(t) \cdot c_{M e}(t)-k_{-p a s} \cdot X(t) \cdot c_{p a s}(t)-k_{a c t} \cdot X(t) \cdot c_{p a s}(t)+k_{-a c t} \cdot X(t) \cdot c_{a c t} \\
\frac{d c_{a c t}}{d t}=k_{a c t} \cdot X(t) \cdot c_{p a s}(t)-k_{-a c t} \cdot X(t) \cdot c_{a c t}
\end{gathered}
$$

Microbial growth in the medium containing no $\mathrm{Cr}(\mathrm{III})$ ions was described with the following Monod equation $^{[33]}$ :

$$
\mu_{C r^{3+}}=0.058 \cdot \frac{S}{0.101+S}
$$

where $\mu_{C r^{3+}}$ is specific growth rate of cells in the presence of $\mathrm{Cr}(\mathrm{III})$ ions.

The effect of $\mathrm{Cr}$ (III) ions on biomass growth rate ${ }^{[33]}$ was assessed previously. The observed decrease of biomass growth rate was described with the following experimental equations:

$$
\mu_{C r^{3+}}=\mu \cdot\left(1-\frac{c_{M e}}{6.33+c_{M e}}\right)
$$

After substituting the equation (13), the following equation was obtained:

$$
\mu_{C r^{3+}}=0.058 \cdot\left(\frac{S}{0.101+S}\right) \cdot\left(1-\frac{c_{M e}}{6.33+c_{M e}}\right)
$$

Therefore, in the presence of $\mathrm{Cr}$ (III) ions in the growth medium, biomass growth can be described with the following dependence:

$$
\frac{d X}{d t}=0.058 \cdot\left(\frac{S}{0.101+S}\right) \cdot\left(1-\frac{c_{M e}}{6.33+c_{M e}}\right) \cdot X
$$

The system of equations describing the mass balance in the system can be solved analytically, after the assumption that at the end of the process pseudostationary state is reached in which the concentrations $c_{M e}, c_{p a s}$ and $c_{a c t}$ do not undergo further changes. The following equation describes pseudo-stationary state:

$$
\frac{d c_{M e}}{d t}=\frac{d c_{p a s}}{d t}=\frac{d c_{a c t}}{d t}=0
$$

The system of equations for the conditions of pseudostationary state, at the end of the process was solved. Two dependencies were obtained:

$$
\begin{aligned}
& k_{\text {-pas }}=0.8125 \cdot \mathrm{k}_{\mathrm{pas}} \\
& k_{\text {-act }}=0.02107 \cdot k_{\text {act }}
\end{aligned}
$$

After substitution to the previous equations, we obtained the following system of dependencies:

$$
\begin{aligned}
& \frac{d c_{p a s}}{d t}=k_{p a s} \cdot X(t) \cdot c_{M e}(t)-0.8125 \cdot k_{p a s} \cdot X(t) \cdot c_{p a s}(t)-k_{a c t} \cdot X(t) \cdot c_{p a s}(t)+0.02107 \cdot k_{a c t} \cdot X(t) \cdot c_{a c t} \\
& \frac{d c_{a k t}}{d t}=k_{a c t} \cdot X(t) \cdot c_{p a s}(t)-0.02107 \cdot k_{a c t} \cdot X(t) \cdot c_{a c t}
\end{aligned}
$$

The system of equations was solved by Mathematica software with the use of non-linear regression method. The obtained equations were very complex, although described experimental results reasonably well.

Due to the complex nature of biochemical processes, in the case of bioaccumulation by Spirulina $s p$., the assumption of the pseudo-stationary state may not be correct. For this reason, we decided not to impose the linear dependence binding parameters $k_{\text {act }}$ with $k_{\text {-act }}$ and $k_{\text {pas }}$ with $k_{\text {-pas }}$ and the above system of equations was described with numerical equations by simultaneous approximation of all four model parameters. The system was solved numerically with self-consisted parameter iteration method. For each iteration, starting parameters were changed with the assessed parameter that brought the lowest error of estimation. The process of parameters bootstrapping is interrupted when a given accuracy of approximation is reached or when the change of neither of model parameters does not improve fidelity of representation. Finally, the following values of the parameters were obtained: $k_{\text {pas }}=5.881(\mathrm{gh})^{-1}, k_{\text {-pas }}=1.391(\mathrm{gh})^{-1}, k_{\text {act }}=$ $0.111\left(\mathrm{gh}^{-1}, k_{\text {-act }}=0.005 \mathrm{l}(\mathrm{gh})^{-1}\right.$. Simultaneously, with the use of least squares methods, estimation error was evaluated as $14 \%$.

Model of artificial neural network: Parallelly with the description of bioaccumulation kinetics with the use of the system of kinetic equations, an attempt of system simulation with the use of algorithm of artificial neural network was performed. Contrary to the kinetic model, algorithm of artificial neural network does not require to implement any kinetic equations a priori, nor to 
assess specific dependencies of the concentration of metal ions during each phase, when compared with the first model. Therefore, methods that use an algorithm of artificial neural network are used in i.e. modelling of non-linear processes in which it is difficult to provide an accurate mathematical equation (or equations) to describe a given process ${ }^{[35]}$.

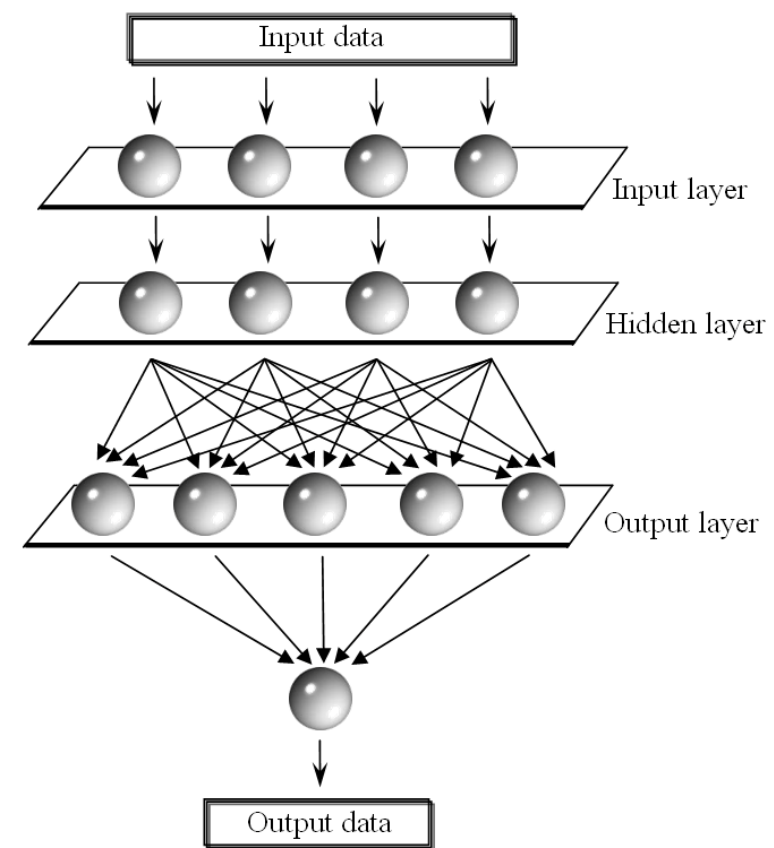

Fig. 3: A representation of a simple 3-layer feedforward artificial neural network with five hidden nodes used in computation of kinetic process.

From over 50 architectures of artificial neural networks ${ }^{[36]}$ in the simulation, the model of training of neural network with the use of Levenberg-Marqardt algorithm with five neurons in the hidden layer was used (Fig. 3). Experimental data were used as the entrance vector (training vector) for $\mathrm{C}_{\mathrm{Cr}(\mathrm{III})}=25.6 \mathrm{mg}$ $\mathrm{kg}^{-1}$. Checking vector (testing vector) was defined basing on data from the studies on mechanism for $\mathrm{C}_{\mathrm{Cr}(\mathrm{III})}=19.2 \mathrm{mg} \mathrm{kg}^{-1}$. Unidirectional neural network of backpropagation algorithm was programmed with the use of MATLAB ${ }^{\circledR}$ software from MathWorks, assuming that construction of neural network should be finished after the value of goal parameter was below 0.05 or after 5000 training generations. Using testing data, error of estimation with the use of neural method was evaluated as $4.5 \%$.

\section{CONCLUSIONS}

The implemented constants in the proposed kinetic equations are of physical character: $k_{\text {pas }}$ represents the rate of metal ions adsorption to the surface of cells, $k_{\text {-pas }}$ - the rate of desorption from the cellular surface (passive stage), $k_{a c t}$ - the rate of active transport of $\mathrm{Cr}$ (III) ions from the outside of cells into the cellular interior, $k_{\text {-act }}$ - the rate of active release of bioaccumulated $\mathrm{Cr}$ (III) ions from the inside of the cells into outside.

The constant $k_{\text {pas }}$ was significantly higher than the other constants. This means that the process of $\mathrm{Cr}$ (III) ions adsorption onto the cellular surface is the quickest stage. The values of $k_{\text {-pas }}$ represent relatively quick process of elution of $\mathrm{Cr}$ (III) ions adsorbed on the cellular surface. The ratio of the constant $k_{p a s}$ to $k_{\text {act }}$ suggests that the process of active transport to the cellular interior was ca. 50 times slower than the process of surface adsorption. Very low value of $k_{\text {-act }}$ reflects very low abilities of Spirulina to release $\mathrm{Cr}$ (III) ions that were previously bioaccumulated. The ratio of $k_{\text {-pas }}$ to $k_{\text {-act }}$ furtherly confirms the assumed simplification. It was confirmed that practically only ions adsorbed on the surface of cells were released by elution. The additional advantage of the application of blue-green algae Spirulina $s p$. in bioaccumulation process is that the release of $\mathrm{Cr}$ (III) ions, that were bioaccumulated inside of the cell, occurs very slowly.

In the present work two different models were presented: kinetic model and model basing on algorithm of artificial neural network as different approach to describe reaction kinetics. In the first case, kinetic model, that possessed higher error, was proposed. The second model based on the analysis of the process mechanism. The model of artificial neural network however is only the mathematical description, not related with the mechanism of the process. Also, an algorithm of network training is in this case only iteration process of minimization of error function. Additionally, the proposed kinetic model possesses four degrees of freedom, while in an algorithm of artificial neural network five neurons in the hidden layer were used.

Generally an algorithm of artificial neural network can be applied in forecasting evolution of concentration of metal ions in the system during the process, separately from the description of reaction kinetics itself. This type of methods can be applied in interpolation, but frequently it fails in the case of extrapolation. Kinetic model however makes it possible to analyze various aspects of the course of bioaccumulation and can be easily interpreted through the assessment of physical nature of all the constants. Finally, reaction rate constants, determined in the first model might be used to quantitatively assess the applicability of Spirulina sp. for the application in 
bioaccumulation of $\mathrm{Cr}$ (III) ions and modelling that would finally lead to commercial applications.

\section{ACKNOWLEDGMENTS}

This research was financially supported by Polish State Committee for Scientific Research (No. 3 T09B 064 27).

\section{REFERENCES}

1. Barron, M.G., 1995. Bioaccumulation and Bioconcentration in Aquatic Organisms. In: Hoffman, D.J., B.A. Rattner, G.A. Jr. Burton, and B.G. Jr. Cairns, Handbook of Ecotoxicology. Boca Raton: CRC Press Inc. p 652-666.

2. Ehrlich, H.L., 1997. Microbes and metals. Appl Microbiol Biotechnol 48: 687-692.

3. Ehrlich, H.L., 1986. What types of microorganisms are effective in bioleaching, bioaccumulation of metals, ore beneficiation and desulfurization of fossil fuels? Biotechnol Bioeng 16: 227-237.

4. Gadd, G.M., 1991. Heavy metal accumulation by bacteria and other microorganisms. Experientia 46: 834-840.

5. Kumblad, L., C. Bradshaw, and M. Gilek, 2005. Bioaccumulation of ${ }^{51} \mathrm{Cr},{ }^{63} \mathrm{Ni}$ and ${ }^{14} \mathrm{C}$ in Baltic Sea benthos. Environmental Pollution 134: 45-56.

6. Perales-Vela, H.V., J.M. Peña-Castro, and R.O. Cañizares-Villanueva, 2006. Review Heavy metal detoxification in eukaryotic microalgae. Chemosphere 64: 1-10.

7. Sunda, W., 2000. Trace Metal-Phytoplankton Interactions in Aquatic Systems. In: Lovley, D.R. editor. Environmental Microbe-Metal Interactions. Washington DC: ASM Press. p 79-107.

8. Cosson, R.P. and J-P. Vivier, 1995. Impact of Metals on Hydrothermal Vent Communities: Bioaccumulation and Detoxification Processes. Mar Environ Res 39 (1-4): 349-349.

9. Darnall, D.W., B. Greene, M.T. Henzi, J.M. Hosea, R.A. McPherson, J. Snedson, and M.D. Alexander, 1986. Selective recovery of gold and other metal ions from an algal biomass. Environ Sci Technol 20: 206-208.

10. Wang, X., and R.C.H. Dei, 2001. Effects of major nutrient additions on metal uptake in phytoplankton. Environ Pollut 111: 233-240.
11. Prince, I.G., Y.P. Ting, and F. Lawson, 1998. Modeling the Uptake of Metal Ions by Living Algal Cells, . In: Wong Y-S, Tam NFY. editors. Wastewater Treatment with Algae. Berlin: Springer-Verlag. p 125-144.

12. Oswald, W. and H.B. Gootas, 1957. Photosynthesis in sewage treatment Trans Am Soc Civ Eng 122: 73-105.

13. Oswald, W.J., 1988. Micro-algae and waste-water treatment. In: Borowitzka, M.A. and L.J. Borowitzka. editors. Micro-Algal Biotechnology. Cambridge: Cambridge University Press. p 305328.

14. Doshi, H., A. Ray, and I.L. Kothari, 2007. Bioremediation potential of live \& dead Spirulina: Spectroscopic, kinetics and SEM studies. Biotechnol Bioeng, 96(6): 1051-1063.

15. Gin, K., Y.Z. Tang, and M.A. Aziz, 2001. Heavy Metal Uptake by Algae. In: Kojima H, Lee YK. editors. Photosynthetic Microorganisms in Environmental Biotechnology. Berlin: Springer. $\mathrm{p}$ 137-169.

16. Liehr, S.K., 1994. Metals removal by algal biofilms. Water Sci Tech 30(11): 59-68.

17. Vilchez, C., I. Garbayo, M.V. Lobato, and J.M. Vega, 1997. Microalgae-mediated chemicals production and wastes removal. Enzyme Microb Tech 20: 562-572.

18. Khoshmanesh, A., F. Lawson, and I.G. Prince, 1996. Cadmium uptake by unicellular green microalgae. Chem Eng J 62: 81-88.

19. Inthorn, D., 2001. Removal of Heavy Metal by Using Microalgae, In: Kojima H, Lee YK. editors. Photosynthetic Microorganisms in Environmental Biotechnology. Berlin: Springer. p 111-137.

20. Khoshmanesh, A., 1997. Cadmium uptake by unicellular green microalgae. Chem Eng J 65: 1319.

21. Khoshmanesh, A., F. Lawson, and I.G. Prince, 1997. Cell surface area as a major parameter in the uptake of cadmium by unicellular green microalgae. Chemical Eng J (British Journal) 65: 13-19.

22. Khoshmanesh, A., Y.P. Ting, and F. Lawson, 1999. A Review on the mathematical modelling of the uptake of heavy metals by micro-organisms. The Chemical Engineering Journal (British Journal) 70: 35-41.

23. Maeda, S. and A. Ohki, 1998. Bioaccumulation and Biotransformation of Arsenic, Antimony and Bismuth Compounds by Freshwater Algae. In: Wong Y-S, Tam NFY. editors. Wastewater Treatment with Algae. Berlin: Springer-Verlag. $\mathrm{p}$ 73-92. 
24. Wilde, E.W. and J.R. Benemann, 1993. Bioremoval of heavy metals by the use of microalgae. Biotech Adv 11: 781-812.

25. Bajguz, A., 2000. Blockade of heavy metals accumulation in Chlorella vulgaris cells by 24epabrassinolide. Plant Physiol Biochem 38: $797-$ 801.

26. Khummongkol, D., G.S. Canterford, and C. Fryer, 1982. Accumulation of Heavy Metals in Unicellular Algae. Biotechnol Bioeng 24: 26432660.

27. Ting, Y.P., F. Lawson, and I.G. Prince, 1989. Uptake of Cadmium and Zinc by the Alga Chlorella vulgaris: Part 1 Individual Ion Species. Biotechnol Bioeng 34: 990-999.

28. Ting, Y.P., F. Lawson, and I.G. Prince, 1990. The uptake of heavy metal ions by algae. Aust J Biot 43: $15-20$.

29. Ting, Y.P., F. Lawson, and I.G. Prince, 1991. Uptake of Cadmium and Zinc by the Alga Chlorella vulgaris: Part II Multi-Ion Situation. Biotechnol Bioeng. 37: 445-455.

30. Chojnacka, K., A. Chojnacki and H. Górecka, 2004. Trace element removal by Spirulina sp. from copper smelter and refinery effluents. Hydrometallurgy 73: 147-153.
31. Zarrouk, C., 1966. Contribution l'e'tude d'une cyanophyce e Influence de divers facteurs physiques et chimiques sur la croissance et la photosynthe'se de Spirulina maxima (Setch et Gardner) Geitler PhD Thesis. University of Paris. Paris, France.

32. Chojnacka, K. and A. Noworyta, 2004. Evaluation of Spirulina $s p$. growth in photoautotrophic, heterotrophic and mixotrophic cultures. Enzyme Microb Technol. 34:461-465.

33. Chojnacka, K., 2003. Heavy metal ions removal by microalgae Spirulina $s p$. in the processes of biosorption and bioaccumulation. $\mathrm{PhD}$ Dissertation. Wroclaw University of Technology. Poland.

34. Chojnacka, K., A. Chojnacki and H. Górecka, 2005. Biosorption of $\mathrm{Cr}^{3+}, \mathrm{Cd}^{2+}$ and $\mathrm{Cu}^{2+}$ ions by blue-green algae Spirulina sp.: kinetics, equilibrium and the mechanism of the process. Chemosphere 59:75-84.

35. Bryjak, J., K. Murlikiewicz, I. Zbyciński and J. Stawczyk, 2000. Application of artificial neural networks to modelling of starch hydrolysis by glucoamylase Bioprocess Eng 23:351-357.

36. Rosenblatt, F., 1961. Principles of Neurodynamics. Washington D.C.: Spartan Press. 